\title{
(4t) Pyrolysis of Negative Photoresists to Fabricate Carbon
Structures for Microelectromechanical Systems
and Electrochemical Applications
}

\author{
Amit Singh, ${ }^{\text {a,z }}$ Jaishankar Jayaram, ${ }^{\text {a Marc Madou, }}$, and Sheikh Akbar ${ }^{\text {a,* }}$ \\ ${ }^{a}$ Center for Industrial Sensors and Measurements, The Ohio State University, Columbus, Ohio 43210, USA \\ ${ }^{b}$ Nanogen, Incorporated, San Diego, California 92121, USA
}

Carbon structures were fabricated by the pyrolysis of photopatterned negative photoresists (SU-8 and photosensitive polyimide) on silicon and fused silica wafers. Results here are compared with those of positive resists published earlier by this group. Negative resist films need exposure to ultraviolet light prior to pyrolysis to produce carbon films. The pyrolysis was carried out in a closed quartz tube furnace in a forming gas $\left(95 \% \mathrm{~N}_{2}, 5 \% \mathrm{H}_{2}\right)$ atmosphere. The pyrolysis process was characterized using a combination of thermogravimetric analysis and differential thermal analysis. The pyrolysis of SU-8 involved gas evolution in a narower range of temperature than polyimide. The adhesion of the carbon film was found to depend on the resist, the substrate, and the heating cycle used. The carbon structures were characterized in terms of their shrinkage during the pyrolysis, the resistivity, the degree of crystallinity and the peak separation in cyclic voltammetry. Carbons derived from pyrolysis of negative resists showed higher resistivity, vertical shrinkage, and peak-to-peak separation voltage than positive resists. Transmission electron microscope results showed a distinct lack of crystallinity even after pyrolysis at $1100^{\circ} \mathrm{C}$, unlike the positive resist derived carbon. (C) 2002 The Electrochemical Society. [DOI: 10.1149/1.1436085] All rights reserved.

Manuscript received May 17, 2001. Available electronically January 29, 2002.

Traditionally, photoresists were used in integrated circuit (IC) fabrication to mask certain areas of the silicon wafer to develop windows in the silicon oxide layer. However with the inclusion of polymers in the materials used for fabricating microelectromechanical systems (MEMS) structures, photoresists are used as structural materials instead of being stripped away. SU-8 has been used extensively to form large aspect ratio thick structures. ${ }^{1,2}$ Polyimide occurs in both photosensitive and nonphotosensitive forms. The nonphotosensitive type is used as the substrate for printed circuit boards. The photosensitive type is used as a photoresist and to form structures. ${ }^{3-7}$ Pyrolysis of the photoresist material in an oxygen-free atmosphere leads to the formation of carbon leaving behind volatile materials. Conventional positive resists based on novolak/ diazonaphthoquinone resins, consist of predominantly aromatic polymers that are extensively cross-linked and are rendered soluble by exposure to ultraviolet (UV) light. Negative resists consist of a mixture of a base rubber-like polymer material that is predominantly aliphatic and a photosensitive cross-linking agent that cross-links the polymer upon exposure to UV light. ${ }^{8-10}$ Thus, though the pyrolysis of films of positive resists not exposed to UV light would still produce carbon films, unexposed negative resist films, due to their low molecular weight and uncross-linked state, would evaporate before pyrolysis can start. Therefore earlier attempts to obtain carbon film from negative resists failed because they were pyrolyzed without exposing to UV. ${ }^{11,12}$ Hence, in the present research, the resists were exposed to UV light even when no feature needed to be developed in the film. When fabricating structures using photolithography, the part left behind in both the positive and negative resists is the highly cross-linked, high boiling point part and, hence, pyrolysis leads to the formation of carbon structures.

Alternative fabrication methodologies include using micromolding instead of photolithography to form the polymeric structures to pyrolyze. Whitesides et al. ${ }^{13}$ used polydimethyl siloxane (PDMS) molds to fabricate poly(furfuryl alcohol) structures using microtransfer molding and microinjection molding. The poly(furfuryl alcohol) produces glassy carbon upon pyrolyzing.

\section{Experimental}

Fabrication.-The substrates used to fabricate the various carbon structures were silicon wafers and fused silica wafers. The silicon wafers used were 2 in. diam, Czochralski (CZ) grown, n-type,

\footnotetext{
* Electrochemical Society Active Member

${ }^{\mathrm{z}}$ E-mail: Singh.124@osu.edu
}

$\langle 100\rangle$ oriented, 13-17 mil thick, 1-20 $\Omega$ resistance wafers supplied by SiliconQuest Inc, Santa Clara, CA. The fused silica wafers were of 3/4 in. diam and 15 mil thick supplied by Valley Design Inc, Westford, MA. The silicon wafers were first treated in a buffered hydrofluoric (BHF) acid solution to remove the native oxide film. The wafers were then dried in a conventional oven at $120^{\circ} \mathrm{C}$ to remove any moisture. The fused silica wafers were cleaned with acetone and isopropyl alcohol to remove any traces of dirt, grease, or dust from the surface. A Speciality Coating Systems model P6700 semiautomatic spin coater with a DV-1000 data access unit was used to coat the substrates with the photoresist. The photoresists used were SU-8 (supplied by Microchem Corp., Newton, MA) and photosensitive polyimide (HD Microsystems, Parlin, NJ). The spin speeds used were 3000 to $6000 \mathrm{rpm}$ for $30 \mathrm{~s}$. SU-8 was soft baked at $90^{\circ} \mathrm{C}$ for $30 \mathrm{~min}$ and polyimide at $55^{\circ} \mathrm{C}$ for $2 \mathrm{~h}$. The resists were then exposed to UV light (Spectroline model BIB-150P UV bulb, $365 \mathrm{~nm}$ UV radiation, $120 \mathrm{~V}, 1.4 \mathrm{~A}$, supplied by Spectronics Corporation) through a contact mask. The exposure time used was 10-15 min, which is more than the recommended time but ensures extensive cross-linking that leads to a sufficiently high molecular weight so that the resist does not disappear on heating, before the onset of pyrolysis. The latent image was developed using the developer and rinse. After postbaking, the resists were pyrolyzed in a closed tube furnace in a forming gas atmosphere $\left(95 \% \mathrm{~N}_{2}, 5 \% \mathrm{H}_{2}\right)$. Before the start of the heating cycle the furnace atmosphere was made inert by flowing gas for $2 \mathrm{~h}$. The samples were heated at a rate of $1-5^{\circ} \mathrm{C} / \mathrm{min}$ and held at the maximum temperature $\left(600-1100^{\circ} \mathrm{C}\right)$ for $60 \mathrm{~min}$ before cooling to room temperature. Lyons et al. ${ }^{14}$ had shown that the difference in shrinkage for different photoresists between pure $\mathrm{H}_{2}$ and pure $\mathrm{N}_{2}$ was about $10 \%$, so a reaction between carbon and $\mathrm{H}_{2}$ does not appear to be a major factor in determining shrinkage. Ranganathan et al. $^{12}$ had also shown the effects of various atmosphere on the shrinkage for a positive resist which suggests that the extent of film shrinkage depends primarily on the oxygen content in the furnace atmosphere. This is why we chose the forming gas atmosphere $\left(95 \% \mathrm{~N}_{2}, 5 \% \mathrm{H}_{2}\right)$.

Characterization.-The carbon films and the pyrolysis process were extensively characterized. Physical properties like the adhesion of the film to the substrate were tested using Scotch tape test and ultrasonic agitation. A Datek profilometer with a vertical resolution of $1 \mathrm{~nm}$ was used to determine the height of the unpyrolyzed photoresist film and the carbon film to calculate the vertical shrinkage. The sheet resistance was evaluated using a four-point probe mea- 
Table I. Comparison of adhesion of carbon derived from SU-8 and polyimide on fused silica and silicon substrates for different thickness and heating rate.

\begin{tabular}{lcc} 
Sample & Silicon & Fused Silica \\
\hline SU-8 at $5^{\circ} \mathrm{C} / \mathrm{min}$ & Adherent & Peeled off \\
PI at $5^{\circ} \mathrm{C} / \mathrm{min}$ & Adherent & Peeled off \\
SU-8 at $1^{\circ} \mathrm{C} / \mathrm{min}$ & Adherent & Adherent \\
PI at $1^{\circ} \mathrm{C} / \mathrm{min}$ & Adherent & Adherent \\
SU-8 at $5^{\circ} \mathrm{C} / \mathrm{min}(8 \mu \mathrm{m}$ thick $)$ & Peeled off & Peeled off \\
PI at $5^{\circ} \mathrm{C} / \mathrm{min}(8 \mu \mathrm{m}$ thick $)$ & Adherent & Peeled off
\end{tabular}

surement. Sheet resistance is not a material property, so resistivity of the carbon film was calculated by dividing the value of sheet resistance by the film thickness.

The pyrolysis process was characterized using thermogravimetric analysis and differential thermal analysis (TGA and DTA) carried out on Perkin-Elmer TGA7 and DTA7. To prepare the samples, a drop of the photoresist weighing about $40 \mathrm{mg}$ was put in the suitable sample holding cup (Pt for TGA, and alumina for DTA). It was then baked in a Lindberg/Blue oven at the soft bake temperature to evaporate the solvent. Then, the solvent free photoresist was exposed to UV light directly, without using any masks, to attain the similar degree of cross-linking as the photoresist after exposure in the photopatterned structure. The exposed resist was then postbaked at the same temperature as that used during regular processing to make structures. Thermal cycle used was same as that for pyrolysis.

A XL300 field emission gun (FEG) scanning electron microscope (SEM) was used to obtain SEM micrographs of fabricated structures. A CM-300 FEG transmission electron microscope (TEM) was used to determine the presence of any microcrystallites. A fast Fourier transformation of the TEM image was used to get the electron diffraction pattern to check the degree of crystallinity. To get the small size needed for the samples to be loaded in a TEM, carbon was scraped off the films and ground to a fine paste in isopropyl alcohol using a quartz mortar and pestle. The paste was then diluted in more isopropyl alcohol to create a suspension of the ground carbon in the isopropyl alcohol. The suspension was kept overnight. After the larger particles visible to the naked eye had settled to the bottom, a drop of the clear liquid with suspended particles in the hundreds of nanometer range was placed on a gold grid. After the isopropyl alcohol had evaporated, the sample was loaded into the microscope.

Electrochemical studies were carried out in a custom-made single compartment cell with platinum auxiliary electrode and $\mathrm{Ag}$ / $\mathrm{AgCl}$ reference electrode. Approximately $0.24 \mathrm{~cm}^{2}$ of the electrode surface, as defined by an O-ring, was exposed to the electrolyte. Bioanalytical systems BAS 100 potentiostat was used for performing cyclic voltammetric studies and a simulation program (Digisim, Bioanalytical Systems, West Lafayette, Indiana) was used for calculating rate constants. Electrochemical characterization was done by evaluating the peak separation between the anodic and cathodic peaks in the cyclic voltammograms in the ferro/ferri cyanide system and in ruthenium hexamine system.

\section{Results and Discussion}

Film adhesion.-The carbon films fabricated were not always adherent to the substrate after pyrolysis. The following three reasons could lead to the film peel-off.

1. Poor adhesion between the substrate and the resist that depends on the roughness of the substrate.

2. Gas evolution during pyrolysis can affect adhesion. Film adhesion would be good if enough time is given for the gases to escape. This could be avoided by using very low heating and cooling rates during pyrolysis (see Table I).

3. Thermal stresses in the film due to the difference in the coefficient of thermal expansion of the film and the substrate.

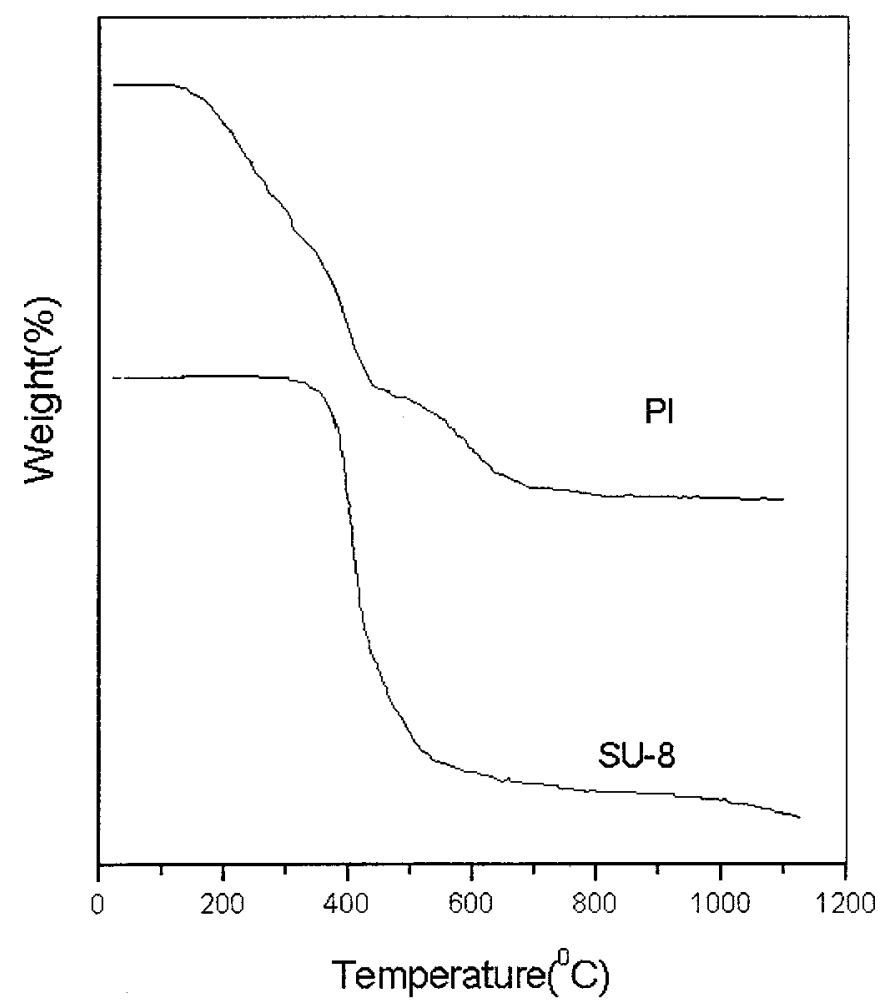

Figure 1. TGA of SU-8 and polymide (PI) photoresists conducted in $5 \% \mathrm{H}_{2}$ and $95 \% \mathrm{~N}_{2}$.

The adhesion of the unpyrolyzed photoresist was tested using ultrasonic agitation and Scotch tape test. The photoresists were always found to be adherent to the substrate, but in some cases, film peeled off during pyrolysis. The degree of detriment to the film due to the gas evolution is determined by the thickness of the photoresist film and the heating rate used in the pyrolysis process because a slower heating rate would mean more time for the gases to escape at each reaction temperature. Thermal stress due to expansion coefficient mismatch can be reduced by choosing a substrate that has a coefficient of thermal expansion closer to the carbon film. The assessment of adhesion of the photoresist and carbon films for the different substrates, photoresists and heating and cooling rates is as shown in Table I.

Thermal expansion coefficient of silicon is $2.3 \times 10^{-6} /{ }^{\circ} \mathrm{C}$ and that of fused silica is $0.55 \times 10^{-6} /{ }^{\circ} \mathrm{C}$. The expansion coefficient of the pyrolyzed carbon is in the range of $2-3.5 \times 10^{-6} /{ }^{\circ} \mathrm{C} .{ }^{15}$ Thus the thermal stress due to the mismatch in the expansion coefficient would be greater for the carbon films on fused silica than on silicon. So in most cases, as seen in Table I, carbon film on fused silica are not adherent. A slower heating rate allows more time for the gas evolution to take place and thus, though the carbon films peel off from fused silica substrates on heating at $5^{\circ} \mathrm{C} / \mathrm{min}$, heating at $1{ }^{\circ} \mathrm{C} /$ min leads to adherent carbon films. Also, thicker photoresists $(8 \mu \mathrm{m})$ lead to peeling off of SU-8 films but the polyimide derived carbon is adherent. This could be explained on the basis of TGA results (Fig. 1 ; discussed later) where we observed a copious gas evolution for SU-8 whereas gas evolution for polyimide is more continuous.

Film shrinkage.-The vertical shrinkage for SU-8 and polyimide is shown in Fig. 2. The vertical shrinkage of SU-8 is much higher than that of polyimide at all temperatures. This is also observed in the TGA results where we observed more weight loss for SU-8 than polyimide. It is also observed that most shrinkage in SU-8 occurs at lower temperatures while for polyimide the shrinkage continues to higher temperatures. This suggests that in the case of SU-8 most of 


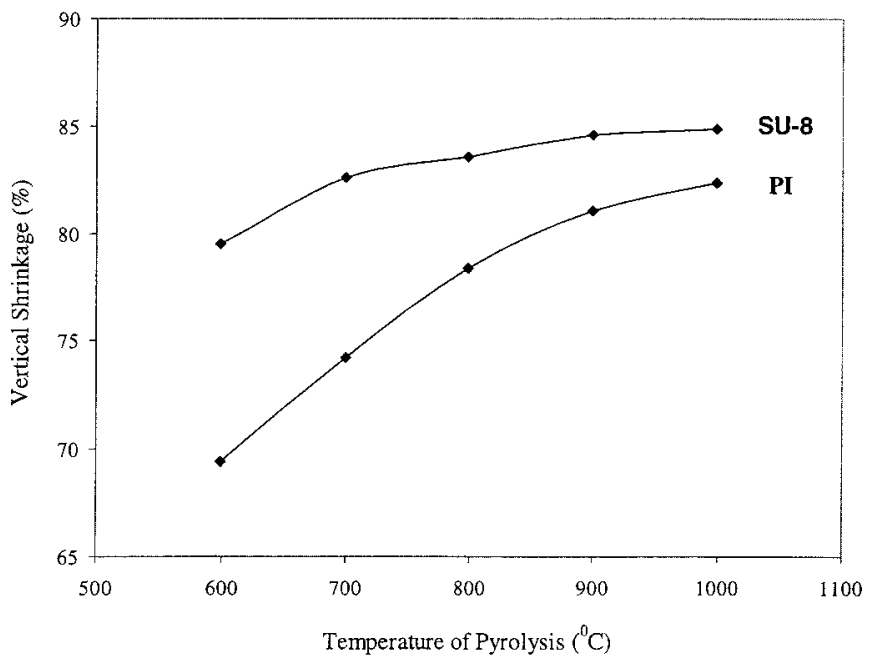

Figure 2. Vertical shrinkage in polyimide (PI) and SU-8 upon pyrolysis in $5 \% \mathrm{H}_{2}$ and $95 \% \mathrm{~N}_{2}$ at various temperatures.

the gas evolution is over by a much lower temperature and there is not much of pyrolysis reactions at higher temperatures, but for polyimide, the pyrolysis gas evolution reactions continue up to higher temperatures.

Thermal analysis.-The TGA data of SU-8 and polyimide is shown in the Fig. 1. It is evident that significant weight loss for SU-8 does not start until about $350^{\circ} \mathrm{C}$ and continues all the way up to $1100^{\circ} \mathrm{C}$. However, in the case of polyimide, the weight loss starts off early, at about $100^{\circ} \mathrm{C}$ and continues all the way up to $700^{\circ} \mathrm{C}$ and then there is not much weight loss. This is also confirmed by the DTA data for SU-8 and polyimide (see Fig. 3), which show a similar trend. The downward spikes in the DTA curve for SU-8 show the sudden onset of different reactions at about 450,700 , and $900^{\circ} \mathrm{C}$ and then there are no more sharp downward spikes in the curve at higher temperatures. On the other hand, the DTA curve for polyimide shows a small downward spike at below $200^{\circ} \mathrm{C}$ and then there are no sudden bursts of reactions/gas evolution at any particular temperature but a gradual thermal degradation of the polymer occurs. Poly-

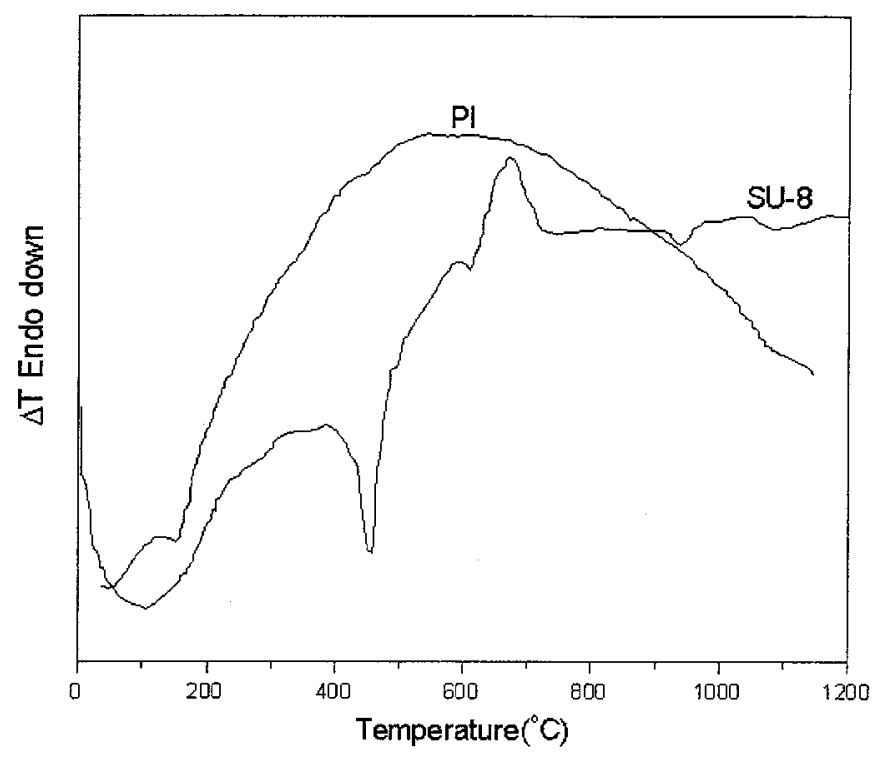

Figure 3. DTA of SU-8 and polyimide photoresists conducted in $5 \% \mathrm{H}_{2}$ and $95 \% \mathrm{~N}_{2}$.

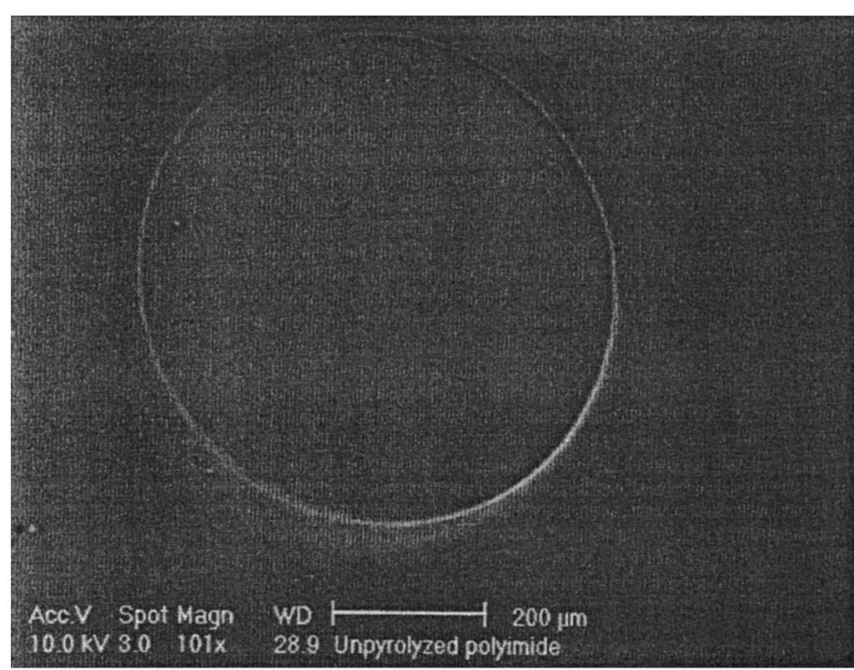

Figure 4. SEM micrograph of the patterned hole structure made from polyimide before pyrolysis.

imide shows endothermic peaks whereas SU-8 shows exothermic peaks. This is not completely understood because exact chemical composition of the resists is not known. So we do not understand the reactions taking place and the gases evolving during pyrolysis. Mass spectroscopy could help in determining the gases evolved during pyrolysis.

These results help explain the following observation. When thick SU-8 films on silicon are pyrolyzed, the resulting carbon film peels off while polyimide derived carbon films of the same thickness heated and cooled at the same rate do not. Based on the results discussed above, during the pyrolysis of SU-8, most of the copious gas evolution occurs in a relatively short temperature range and this undermines the adhesion of the film to the substrate while in the case of polyimide, the pyrolysis is in the form of a gradual thermal degradation without any sudden bursts of gas evolution at any particular temperature, and thus relatively thicker films of polyimide are able to produce carbon films still adherent to the substrate. The results of the thermal analysis have been treated in a qualitative manner as they help explain the observed phenomena, but a more complete quantitative analysis in conjunction with a synchronized gas analysis system like Fourier transform infrared spectroscopy (FTIR) would greatly aid in a thorough understanding of the pyrolysis chemistry.

Microscopy.-Photolithography was used to fabricate carbon structure based on negative resist, polyimide. The structure consists of a number of holes on a mask. Figure 4 shows a SEM micrograph of one such hole of unpyrolyzed structure after postbaking, and Fig. 5 shows the SEM after pyrolysis. The final dimension of the hole was found to be about $90 \%$ of the original dimension. As the films remain adherent to the substrate all along the edges, the decrease in dimension of the holes can only be attributed to the flow of the resist during pyrolysis. Negative resists are known to flow due to their low glass transition temperature because of their lower molecular weight (polyimide has a glass transition temperature of $360^{\circ} \mathrm{C}$ ). Thus it is consistent with the reduction of the hole dimension. Also, the surface of the carbon film is very smooth and pore free, which is to be expected when the pyrolysis occurs in the glassy liquid-like resist.

The high resolution image and electron diffraction pattern for SU-8 derived carbon are shown in Fig. 6 and 7, respectively. The high resolution image and electron diffraction pattern for polyimide derived carbon are shown in Fig. 8 and 9. As can be seen from the high resolution images, the carbon structure is pore free even at the nanolevel. The electron diffraction pattern shows neither spots nor rings corresponding to any crystal planes that might be present in 


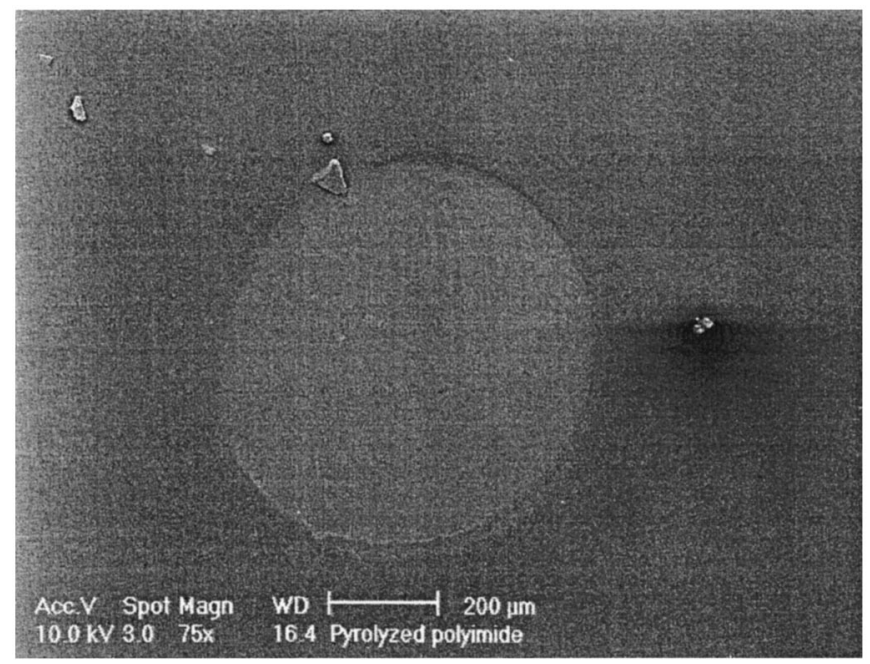

Figure 5. SEM micrograph of the carbon structure made by pyrolyzing patterned polyimide in $5 \% \mathrm{H}_{2}$ and $95 \% \mathrm{~N}_{2}$ at $1100^{\circ} \mathrm{C}$.

the structure, which is in accordance with the phase contrast image. The images are representative of the entire sample as none of the many particles considered showed any crystallinity.

The distinct lack of crystallinity even in the carbon obtained by pyrolysis at $1100^{\circ} \mathrm{C}$ is at odds with the findings in the case of positive resists as reported earlier. ${ }^{12}$ The positive resist derived carbon (specifically AZ4330 derived carbon) showed distinct (002) atomic planes. ${ }^{12}$ This can be explained by the fact that the structure of positive resists consists of long polymer chains whose monomer units are aromatic in nature, that is, their structure is based on the hexagonal benzene ring structure. However, most negative resists have long aliphatic (straight chain) carbon chains cross-linked by a cross-linking molecule. ${ }^{9}$ The process of complete graphitization of carbon by heating at atmospheric pressure reaches completion only at $2700^{\circ} \mathrm{C}$, but the nucleation of small graphitic nanocrystallites

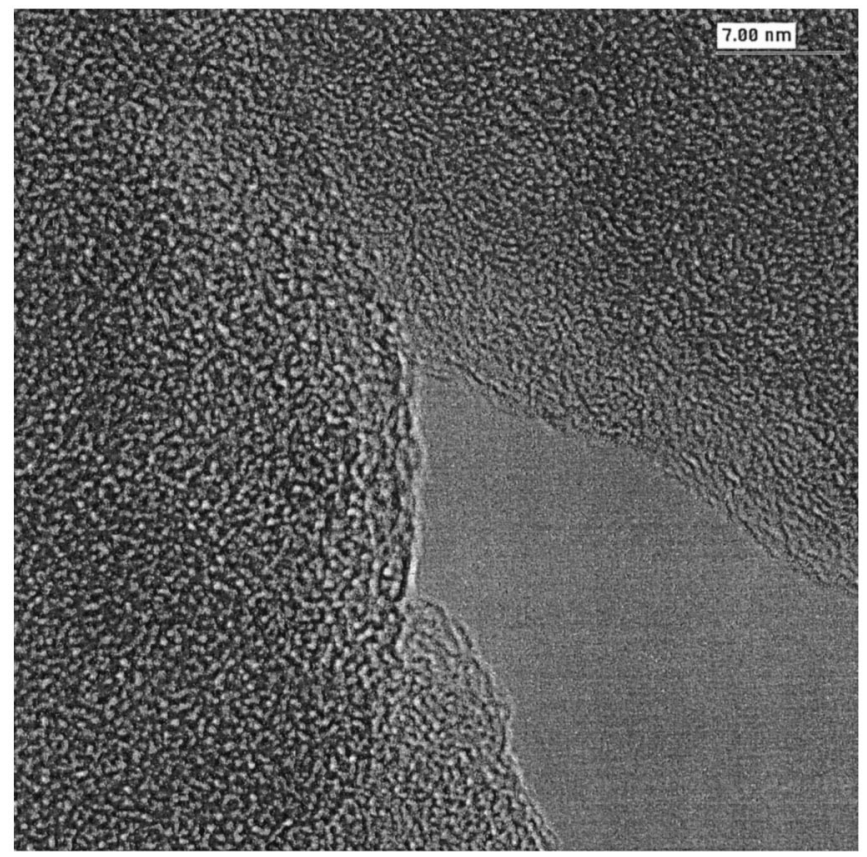

Figure 6. TEM image of carbon derived by pyrolyzing SU-8 in $5 \% \mathrm{H}_{2}$ and $95 \% \mathrm{~N}_{2}$ at $1100^{\circ} \mathrm{C}$

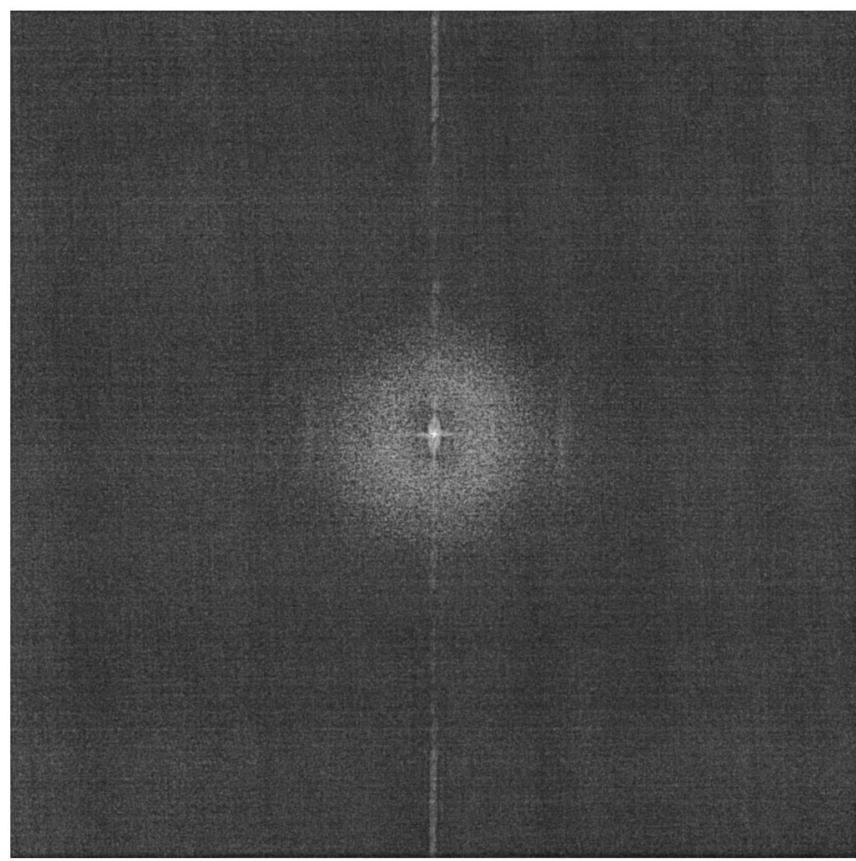

Figure 7. Electron diffraction pattern for carbon film derived from SU-8 by pyrolyzing at $1100^{\circ} \mathrm{C}$.

starts at lower temperatures, even as low as $1000^{\circ} \mathrm{C}$. In the case of positive resists, because the carbon atoms are already in the hexagonal ring positions, the bond rearrangement needed to form the ringed hexagons of graphite would not be as drastic as that for the straight chain based negative resists. Hence the nanosized graphite-like particles start occurring in positive resists at a lower temperature than in the negative resists. The negative resists too would eventually start showing increasing degree of crystallinity until complete

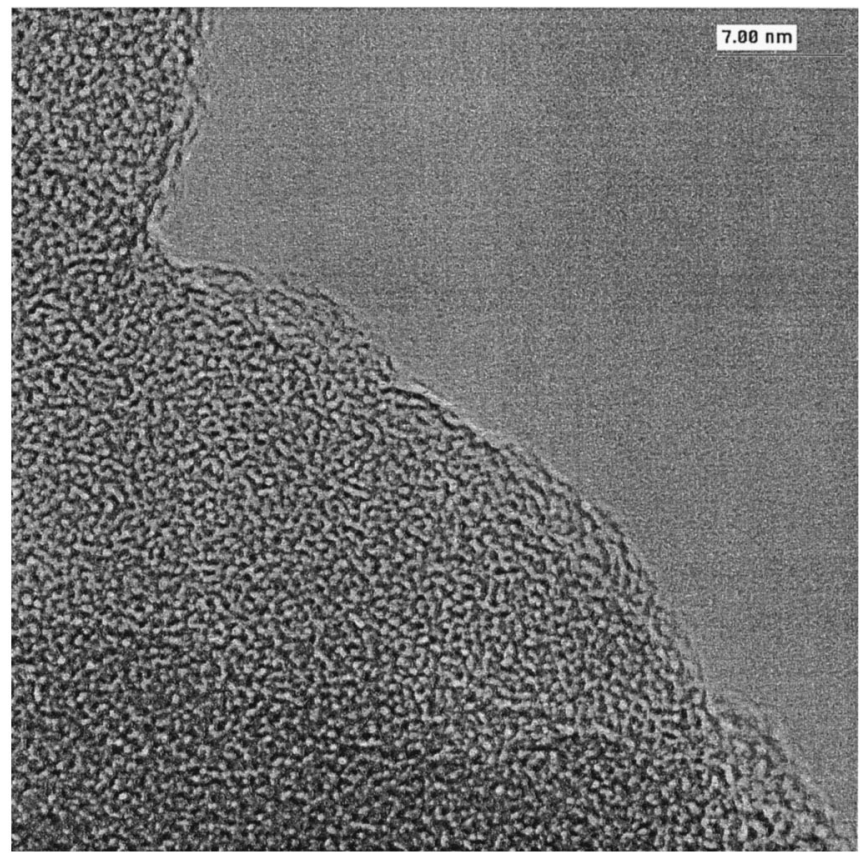

Figure 8. TEM image of carbon derived by pyrolyzing polyimide in $5 \% \mathrm{H}_{2}$ and $95 \% \mathrm{~N}_{2}$ at $1100^{\circ} \mathrm{C}$. 


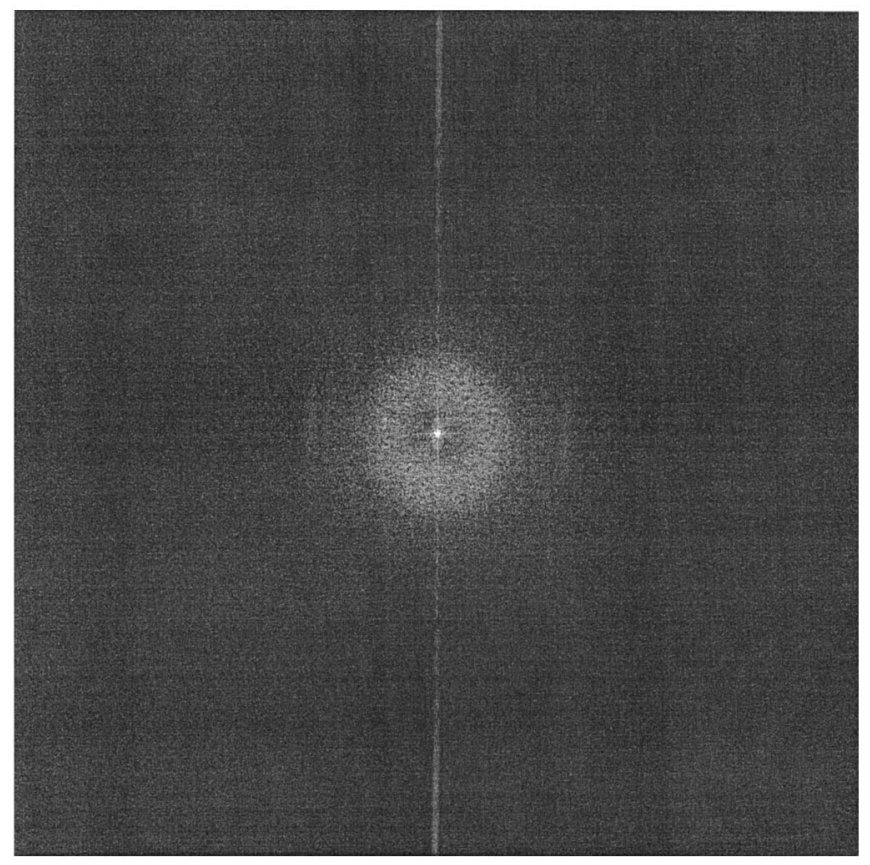

Figure 9. Electron diffraction pattern for carbon derived from polyimide after pyrolysis at $1100^{\circ} \mathrm{C}$.

graphitization at $2700^{\circ} \mathrm{C}$, as observed by Takechi et al. ${ }^{16}$ for polyimide derived carbon.

Carbon film resistivity.-Figure 10 shows the variation of the resistivity of the pyrolyzed carbon film at different temperatures. The general trend observed in both the curves is that the resistivity decreases with increase in temperature. At higher temperatures, the resistivity falls as the temperature of pyrolysis decreases, spanning a wide range of values from the low similar to those found in conducting glassy carbon to high for insulating material. The decrease in resistivity with increase in temperature is attributed to the degree of graphitization. The higher the temperature of pyrolysis higher would be the extent of graphitization and thus lower resistivity. The resistivity of the carbon film derived from SU-8 is slightly lower than that of the polyimide. The resistivity of the films depends on the extent of graphitization and which in turn depends on the poly-

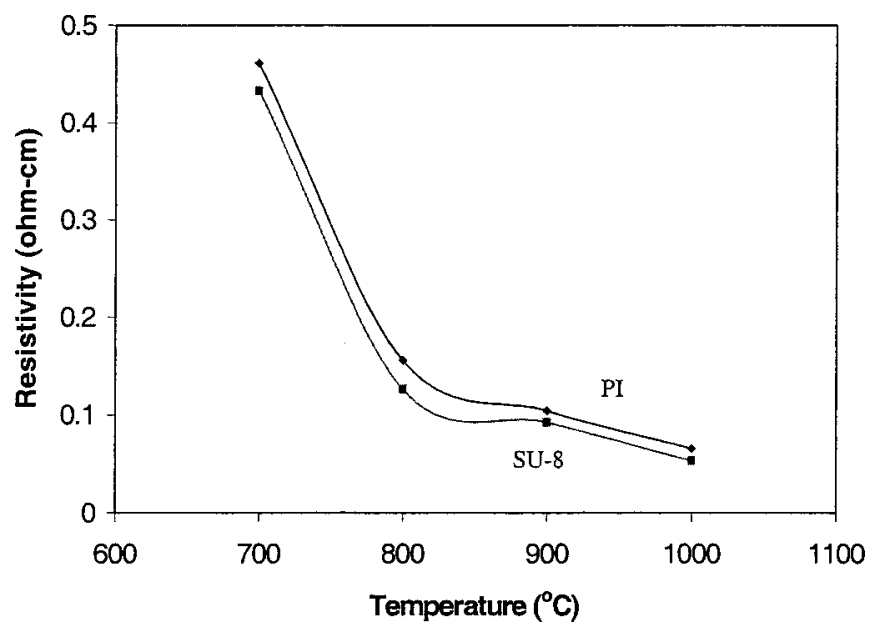

Figure 10. Resistivity of carbon derived from SU-8 and polyimide by pyrolysis in $5 \% \mathrm{H}_{2}$ and $95 \% \mathrm{~N}_{2}$ at different temperatures.

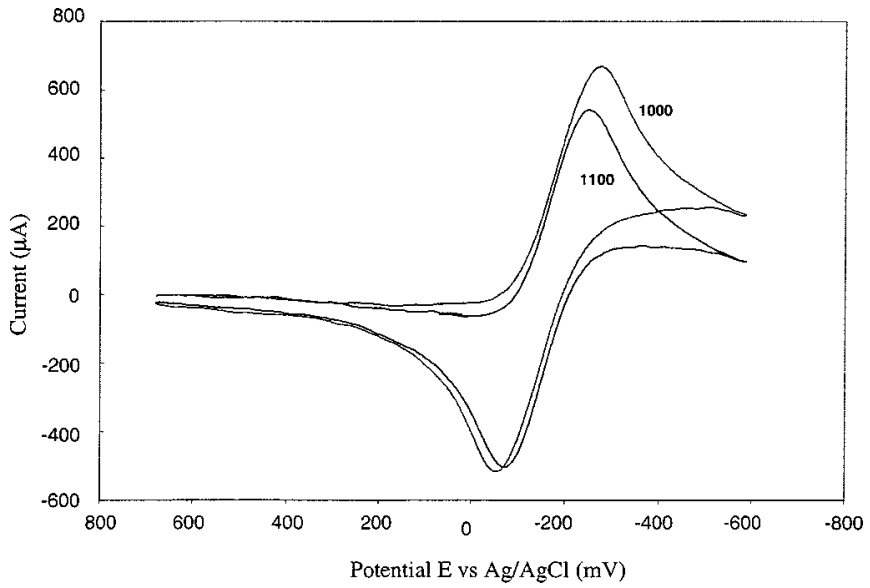

Figure 11. Cyclic volyammetry of SU-8 derived carbon pyrolyzed at 1000 and $1100^{\circ} \mathrm{C}$ in a potassium ferro/ferricyanide solution scanned at $2 \mathrm{~V} / \mathrm{s}$.

meric precursor, thus the values of resitivity would strongly depend on the photoresist being pyrolyzed. This explains why the values of resistivity for the two films are different.

Electrochemical characterization.-The cyclic voltammograms of $\mathrm{Fe}(\mathrm{CN}){ }_{6}^{3-14-}$ obtained on the surface of SU-8 derived carbon films pyrolyzed in $5 \% \mathrm{H}_{2}$ and $95 \% \mathrm{~N}_{2}$ at several temperatures is shown in Fig. 11. It is observed that by increasing the temperature of pyrolysis, the oxidation and reduction peaks become closer, implying that the $\Delta E_{\mathrm{P}}$ (difference in peak-to-peak potential) values decrease, while the peak currents increase. This is an indication that by pyrolyzing the carbon films at higher temperatures, one obtains a film that is more conducive to electron transfer at the electrode surface. This is in agreement with the observations in the sheet resistivity, where it was observed that higher temperatures of pyrolysis lead to more conductive films.

Table II shows the variation in $\Delta E_{\mathrm{p}}$ for the redox systems, $1 \mathrm{mM}$ $\mathrm{Fe}(\mathrm{CN})_{6}^{3-/ 4-}$ in $1 \mathrm{M} \mathrm{KCl}$ and $1 \mathrm{mM} \mathrm{Ru}\left(\mathrm{NH}_{3}\right)_{6}^{3+/ 2+}$ in $1 \mathrm{M} \mathrm{KCl}$ at various scan rates for the SU-8 photoresist films pyrolyzed at 1000 and $1100^{\circ} \mathrm{C}$. On carbon electrode surfaces free from surface impurities, both these redox systems are shown not to depend on the carbon surface structure. ${ }^{17}$ It can be seen from the table that higher pyrolysis temperature leads to faster electron transfer kinetics as observed through the decrease in the $\Delta E_{\mathrm{p}}$. It has been established previously ${ }^{12}$ that the resistance of electrode film plays a significant role on the observed $\Delta E_{\mathrm{p}}$ due to ohmic potential drop associated with it. Knowing the sheet resistance values and electrode dimensions, the electrode resistance can be calculated and a correction to the $\Delta E_{\mathrm{p}}$ can be applied. The electron transfer rate constants for these two redox systems were calculated after correcting the $\Delta E_{\mathrm{p}}$ for this ohmic error. The rate constants for $\mathrm{Fe}(\mathrm{CN})_{6}^{3-/ 4-}$ on the films pyro-

Table II. Difference in peak potentials $\left(\Delta E_{\mathrm{p}}, \mathrm{mV}\right)$ of cathodic and anodic peaks for pyrolyzed photoresist film at 1100 and $1000^{\circ} \mathrm{C}$ at various scan rates.

Temperature of pyrolysis $\left({ }^{\circ} \mathrm{C}\right)$

\begin{tabular}{crr}
\multicolumn{3}{c}{ Scan rate } \\
\hline $200 \mathrm{mV} / \mathrm{s}$ & $2 \mathrm{~V} / \mathrm{s}$ & $20 \mathrm{~V} / \mathrm{s}$ \\
77 & 112 & 212 \\
77 & 106 & 183 \\
& & \\
75 & 112 & 208 \\
74 & 96 & 166
\end{tabular}


lyzed at different temperatures are $0.019 \mathrm{~cm} / \mathrm{s}$ at $1000^{\circ} \mathrm{C}$ and 0.026 $\mathrm{cm} / \mathrm{s}$ at $1100^{\circ} \mathrm{C}$. The rate constants for $\mathrm{Ru}\left(\mathrm{NH}_{3}\right)_{6}^{3+/ 2+}$ are 0.017 $\mathrm{cm} / \mathrm{s}$ and $0.025 \mathrm{~cm} / \mathrm{s}$, respectively. The $\Delta E_{\mathrm{p}}$ values for these redox systems on pyrolyzed polyimide films are slightly larger than those for SU-8, consistent with the higher resistivity of the polyimide films. These rate constants are slightly lower than the values reported for pyrolyzed positive photoresist films $(0.055 \mathrm{~cm} / \mathrm{s}$ for $\mathrm{Ru}\left(\mathrm{NH}_{3}\right)_{6}^{3+/ 2+}$ and $0.042 \mathrm{~cm} / \mathrm{s}$ for $\left.\mathrm{Fe}(\mathrm{CN})_{6}^{3-/ 4-}\right)$, but still are within the values reported for various pyrolyzed carbon films. ${ }^{12}$ This lower rate constant may be due to lesser graphitization observed in negative photoresist on pyrolysis. In the case of carbon films obtained by pyrolyzing positive photoresist, the increasing electron transfer rate with pyrolysis temperature has been attributed to the increasing degree of graphitization. Since the carbon films from the negative photoresist are more amorphous, the slower electron transfer rates are not surprising. It is quite possible that these carbon films will show a significantly different behavior for other redox systems that depend on the surface structure of carbon electrodes. These results do establish the suitability of these electrodes in electrochemical applications.

\section{Conclusions}

Carbon structures were fabricated by the pyrolysis of photopatterned SU-8 and photosensitive polyimide films on silicon and fused silica wafers. Exposure to UV light was necessary to obtain carbon even in featureless photoresist films because, otherwise, the resist would be in the uncross-linked state and would disappear before the pyrolysis had even begun. The flow inherent to negative resists leads to a decrease in the lateral shrinkage in the carbon film compared to the positive photoresist film. Thermal analysis gives a qualitative understanding of the pyrolysis and must be used to tailor heating cycles suitable for individual resists. During the pyrolysis of SU-8, the gas evolution occurs in a shorter temperature range than in polyimide and hence thicker films or faster heating rates lead to the peeling off of carbon films faster in SU-8 than in polyimide.

Peeling off of the carbon films occurs due to a combination of thermal mismatch, gas evolution, and poor adhesion of the resist to the substrate. Increasing temperatures of pyrolysis lead to larger vertical shrinkage and lower sheet resistivity. Negative resists are very sensitive to oxygen and tend to flow, and hence, their vertical shrinkage is more than that for positive resist derived carbon. The shrinkage for SU-8 was greater in magnitude than for polyimide at all temperatures. TEM analysis shows a pore-free amorphous film. Cyclic voltammetry in ferro/ferricyanide and ruthenium hexamine shows a fairly reversible behavior, comparable to that of positive resists derived carbon.

The Ohio State University assisted in meeting the publication costs of this article.

\section{References}

1. J. M. Shaw, J. D. Gelorme, N. C. LaBianca, W. E. Conley, and S. J. Holmes, IBM J. Res. Dev., 41, 81 (1997).

2. H. Lorenz, M. Despont, M. Fahrni, N. LaBianca, P. Vettiger, and P. Renaud, $J$. Micromech. Microeng., 7, 121 (1997).

3. M. K. Ghosh and K. L. Mittal, Polyimides: Fundamentals and Applications, Marcel Dekker, New York (1996).

4. M. I. Bessonov and V. A. Zubkov, Polyamic Acids and Polyimides: Synthesis, Transformations, and Structure, CRC Press, Boca Raton, FL (1993).

5. B. S. Moon, Ph.D Thesis, University of Akron, Akron, OH (1996).

6. K. Horie and T. Yamashita, Photosensitive Polyimides: Fundamentals and Applications, Technomic Publishing AG, Basel, Switzerland. (1995).

7. G. R. Langlade, P. Monjol, and H. Sekiguchi, Polymer, 38 (19), 4965 (1997).

8. E. Reichmanis, O. Nalamasu, M. F. Houlihan, and A. E. Novembre, Polym. Int., 48, 1053 (1999).

9. M. J. Madou, Fundamentals of Microfabrication, CRC Press, New York (1997).

10. D. J. Elliot, Integrated Circuit Fabrication Technology, McGraw-Hill, New York (1982).

11. S. M. Majji, M.S. Thesis, The Ohio State University, Columbus, OH (1999).

12. S. Ranganathan, R. McCreery, S. M. Majji, and M. J. Madou, J. Electrochem. Soc., 147, 277 (2000)

13. G. M. Whitesides, C. Marzolin, S. T. Brittain, and O. J. A. Schueller, Chem. Mater, 9, 1399 (1997).

14. A. M. Lyons, L. P. Hale, and C. W. Wilkins, J. Vac. Sci. Technol., B, 3, 447 (1985).

15. K. Kinoshita, Carbon-Electrochemical and Physicochemical Properties, John Wiley \& Sons, New York (1988).

16. T. Takeichi, Y. Eguchi, Kaburagi, Y. Hishiyama, and M. Inagaki, Carbon, 37, 569 (1999).

17. R. L. McCreery, in Interfacial Electrochemistry, A. Wieckowski, Editor, Marcel Dekker, Chap. 35, New York (1999). 